\title{
LAS FRANQUICIAS ECUATORIANAS Y SU CONTRIBUCIÓN EN LA GENERACIÓN DE EMPLEO
}

\section{THE ECUADORIAN FRANCHISES AND THEIR CONTRIBUTION IN THE GENERATION OF EMPLOYMENT}

Recibido: $16 / 10 / 2018$

Aceptado: 10/05/2018

\author{
Zlata D. Borsic Laborde ${ }^{1}$ \\ (zdborsic@espe.edu.ec) \\ Azucena M. Maya Carrillo² \\ (ammaya@espe.edu.ec) \\ William M. Aigaje Sierra ${ }^{3}$ \\ (wmaigaje@espe.edu.ec)
}

\section{Resumen}

El presente estudio nace de una investigación previa, realizada con el objetivo de caracterizar las franquicias de capital ecuatoriano e identificar su aporte en la generación de fuentes de empleo; para ello se tomó en consideración que las franquicias permiten replicar un negocio de éxito, que crece con facilidad y posee una alta probabilidad de generar fuentes de empleo, por lo que era necesario caracterizar las franquicias nacionales. El método de investigación utilizado tuvo diseño no experimental de nivel descriptivo, con enfoque mixto. Para la fase cualitativa, los datos se recolectaron mediante una entrevista semi estructurada, aplicada a los directores de las asociaciones de franquicias más representativas del país; en cambio, para la fase cuantitativa se aplicó un cuestionario al total de la población de franquicias nacionales que, al momento de realizar la investigación, en el período abril-agosto de 2016, fue de 45 franquicias. Los resultados obtenidos reflejan que las franquicias ecuatorianas, se enfocan en la industria alimenticia, farmacéutica y de la construcción, las cuales poseen 2.355 establecimientos y generan 12.114 fuentes de empleo, lo que posiciona a las franquicias como un modelo de negocio que permite generar empleo en el país.

Palabras Clave: Desarrollo, empleo, expansión comercial, franquicias, laboral, modelo de negocio.

1 Departamento de Ciencias Económicas, Administrativas y de Comercio, Universidad de las Fuerzas Armadas ESPE, Sangolquí - Ecuador, ORCID: 0000-0001-8145-2313.

2 Departamento de Ciencias Económicas, Administrativas y de Comercio, Universidad de las Fuerzas Armadas ESPE, Sangolquí - Ecuador, ORCID: ORCID: 0000-0001-5795-1593.

3 Departamento de Ciencias Económicas, Administrativas y de Comercio, Universidad de las Fuerzas Armadas ESPE, Sangolquí - Ecuador, ORCID: 0000-0001-8776-3681. 


\section{Abstract}

The present study is the result of a previous investigation, carried out with the objective of characterizing the Ecuadorian capital franchises and identifying their contribution in the generation of employment sources; for this, it was taken into consideration that franchises allow the replication of a successful business, which grows with ease and has a high probability of generating sources of employment, it was necessary to characterize national franchises. The research method used had a non-experimental design at a descriptive level, with a mixed approach. For the qualitative phase, the data was collected through a semi-structured interview, applied to the directors of the most representative franchise associations in the country; On the other hand, for the quantitative phase, a structured questionnaire was applied consisting of 31 questions, to the total of the population of national franchises that, at the time of conducting the research, in the period AprilAugust 2016, was 45 franchises. The results obtained show that the Ecuadorian franchises are focused on the food, pharmaceutical and construction industries, which have 2,355 establishments and generate 12,114 sources of employment, which positions franchises as a business model that generates employment in the country.

Keywords: Development, employment, commercial expansion, franchising, labor, business model. 


\section{Introducción}

Se ha identificado que existe preocupación a nivel mundial, por causa de la falta de fuentes de empleo, problema para el cual el modelo de negocio de las franquicias representa una solución. De igual manera, los autores del presente estudio detectaron que la investigación referente a las franquicias que operan con capital ecuatoriano y su contribución a la generación de empleo a nivel nacional, es escasa, sin embargo, existen varias investigaciones relacionadas con el tema de las franquicias (Palomeque y Ramírez, 2012; Cajamarca y Granda, 2012; Guerrero, 2015).

Los franquiciados obtienen la oportunidad de ser empresarios, gracias al respaldo con el que contribuye el franquiciado, mediante la entrega de todo el conocimiento para manejar un negocio de éxito comprobado, llámese: asistencia técnica, administrativa, récord financiero que respalda el acceso a créditos, el hecho de no requerir experiencia previa y en algunos casos formación continua ( $\mathrm{Pa}-$ vón-Villegas y Vargas-Hernández, 2016); por lo que las franquicias, debido a sus características, representan un negocio en el que el riesgo a fracasar es menor "en comparación con la creación de un negocio propio y lo que contribuye en el éxito de este tipo de negocios es el apego a los procedimientos, al cumplimiento de las obligaciones del franquiciado", además del estudio del perfil del postulante a adquirir la franquicia (Pavón-Villegas y Vargas-Hernández, 2016, p. 90).

El presente estudio se basa en los resultados obtenidos en un trabajo de titulación que se realizó con anterioridad (Aigaje-Sierra, 2017), dirigido a obtener la caracterización de las franquicias de origen ecuatoriano, existentes al momento de realizar el estudio, con el propósito de identificar su capacidad para generar fuentes de empleo en el país.

Vásquez-Gómez (2017) define a la franquicia como una forma de expansión comercial, mediante la cual dos empresarios independientes, uno en calidad de dueño de un negocio, que se lo denomina franquiciador o franquiciante, le cede al segundo, llamado franquiciado, el derecho a explotar de manera exclusiva un modelo de negocio, en un mercado específico y por un plazo de tiempo determinado, y al mismo tiempo el deber de comercializar los productos o servicios 
de su marca, utilizando el concepto de negocio y su política comercial; en contraparte, el franquiciador recibe el pago de unas contraprestaciones financieras establecidas con anterioridad, tales como: un canon de entrada y comisiones periódicas, en función del volumen de ventas; de lo que se denota que las franquicias constituyen un modelo empresarial que se destaca porque presenta un desarrollo sostenido y ha contribuido en la modernización del comercio (Asociación Mexicana de Franquicias, 2017); motivo por el cual, los autores del presente estudio buscaron caracterizar las franquicias con capital de origen ecuatoriano, con el fin de identificar su aporte en la generación de empleo.

\subsection{Origen de las franquicias}

El origen de las franquicias no es un concepto nuevo, pues este tipo de actividad se ha realizado desde la Edad Media, sin embargo, como modelo de negocio, se ha aplicado desde el siglo pasado y ha sido sujeto de innovaciones con el transcurso del tiempo. A nivel de Latinoamérica, de acuerdo con Medina (2016), los países que poseen un mayor número de establecimientos franquiciados son Brasil (114.409) y México (73.000); en este sentido, Guerrero (2015) señala que estos dos países latinoamericanos emplean a 1.775 .566 personas, de las cuales 1.025 .566 corresponden a las franquicias de Brasil y 750.000 empleos corresponden a México.

Es así que se ha identificado a Estados Unidos y Francia, como los países con mayor desarrollo en términos de franquicias, sistema de negocios que aparecieron en respuesta a problemas específicos, tales como: rigidez de las leyes de competencia, las cuales prohibían la integración vertical entre vendedores y fabricantes; la cual, según Ramos-Mallarino y Forero-Rodríguez (2014, p. 268) "constituye la unificación de procesos y recursos con que cuenta una unidad y lo que pueden hacer por ellos mismos en la institución"; así mismo, Fernández (2017) señala que la integración vertical, se genera en el momento en que una organización participa en múltiples segmentos de la cadena de producción de un bien y/o servicio; además se prohibía la asociación bajo contrato con detallistas independientes para obtener la exclusividad de uso de una marca en un área geográfica determinada (Pavón-Villegas y Vargas-Hernández, 2016; Llain-Arenilla e Insignares-Cera, 2016). 


\subsection{Definiciones de franquicia}

Existen algunas definiciones del término franquicia, es así que el diccionario de la Real Academia Española (RAE, 2014) define a la franquicia como la concesión de derechos de explotación de un producto, actividad o marca, que otorga una organización a uno o varios individuos, en un territorio determinado. Una franquicia genera una relación continua entre la empresa que creó un negocio (franquiciante), la cual ofrece asistencia administrativa, así como el derecho de uso de la marca ya consolidada en el mercado a otra empresa (franquiciatario), a cambio de pagos del propietario de la unidad comercial individual. La combinación del franquiciante con uno o varios franquiciatarios se conoce como un sistema de franquicias. En cambio, las dos partes que intervienen en el contrato de franquicia son el franquiciante y el franquiciado; el franquiciante es la persona dueña de los derechos de explotación de una marca y poseedor del conocimiento de producción o comercialización, está encargado de supervisar el correcto funcionamiento de las franquicias, ofreciendo asistencia técnica y soporte continuo; por su parte el franquiciado tiene el beneficio de invertir en un negocio probado y la oportunidad de ingresar en economías de escala pero a la vez el formar parte de una franquicia limita las oportunidades de innovar y ser totalmente independiente.

Llain-Arenilla e Insignares-Cera (2016), coinciden en que el contrato de franquicia le facilita al propietario de un negocio, denominado franquiciador o franquiciante, poner a disposición de otro individuo, denominado franquiciado, la posibilidad de hacer uso en un determinado mercado, del modelo de negocio del primero, a cambio de una contraprestación económica. En definitiva, los autores citados, coinciden en que la franquicia consiste en un acuerdo o contrato entre dos partes, por el cual el franquiciante le permite al franquiciado, comercializar un determinado producto o servicio, utilizando la marca comercial del franquiciante, en un territorio específico, contra el pago de un derecho de entrada y comisiones por ventas, durante un período de tiempo determinado; condiciones que van a variar, dependiendo del tipo de franquicia de la que se trate. 


\subsection{Tipos de franquicias}

Palomeque y Ramírez (2012) clasifican a las franquicias en dos grupos, un primer grupo corresponde a aquellas que prestan un servicio, tales como: a) restaurantes, b) hoteles, c) transporte, d) servicios financieros, e) comunicaciones, f) educación, g) servicios profesionales, h) el Gobierno, entre otros; el segundo grupo es el de las franquicias que se dedican a las actividades relacionadas con la compra y la venta de los productos y servicios, dentro de los cuales se puede mencionar: a) venta de productos farmacéuticos y de ferretería; y las franquicias del sector manufacturero, tales como: a) empresas que se dedican a la producción, elaboración y conservación de carne, pescado, entre otros productos alimenticios, b) fabricación de productos químicos, de papel y sus productos y c) productos minerales no metálicos.

Por otro lado, la Asociación Mexicana de Franquicias (2017), señala que existen tres tipos de franquicia, tales como: las de formato de negocio, las de distribución exclusiva y las de producto y marca; a su vez, cada tipo de franquicia puede encajar en una categoría, las cuales pueden ser: individual, múltiple, regional o maestra-internacional.

Una vez revisadas las principales tipologías de las franquicias, de acuerdo con varios autores, se denota que las franquicias actúan como entes dinamizadores de la economía en los diversos sectores en los que tienen su campo de acción, ya que generan un incremento en la oferta de bienes y servicios; es por ello que algunos emprendedores han creado franquicias cuya idea de negocio y capital, tiene origen ecuatoriano, emprendimientos que han alcanzado un verdadero desarrollo en los últimos años.

\subsection{Franquicias ecuatorianas}

De acuerdo con la investigación realizada por la Cámara de Comercio Ecuatoriano-Americana y Prom-Perú (2011), el mercado ecuatoriano está dominado por las franquicias procedentes de los Estados Unidos (80\%), también existen franquicias procedentes de Colombia, Venezuela y otros países (10\%), además de las locales (10\%). Puntualmente, en Ecuador este modelo de negocios empieza en el año 1967, con la llegada de las franquicias internacionales, principalmen- 
te provenientes de los Estados Unidos. La Cámara de Comercio EcuatorianoAmericana y Prom-Perú (2011) ha identificado que el porcentaje de crecimiento de las franquicias en Ecuador aún es pequeño (4\%), sin embargo, en la última década este tipo de negocios se han desarrollado de manera progresiva, lo que se refleja en el número de establecimientos que poseen las franquicias, cuya proporción de crecimiento es mayor (25\%).

De manera posterior, en el año 1992 empezaron a surgir las franquicias de capital ecuatoriano, tales como: Yogurt Persa, Farmacias Cruz Azul, Docucentro Xerox, Restaurante PIM'S, Cellshop, entre otras. Aunque el mayor repunte de las franquicias en el país se dio a partir del año 2000, cuando Ecuador sufrió la transición del sucre como su moneda hacia la adopción del dólar americano como moneda nacional (Cajamarca y Granda, 2012); el esfuerzo de varios empresarios del país para expandir sus empresas mediante el modelo de negocios basado en franquicias se vio reflejado con mayor notoriedad a partir del año 2005, año en el que se llegó a contabilizar no menos de 35 franquicias ecuatorianas, entre las que se destacan: Los Cebiches de la Rumiñahui, Churrín-Churrón, Frutanga, Pañaleras Pototín, Expocolor, Bopan, Disensa, entre otras (Cajamarca y Granda, 2012).

De manera tal que muchos propietarios de negocios locales, especialmente dedicados al servicio de alimentación, que están ubicados en las principales ciudades del país, tales como: Quito, Guayaquil, Cuenca, Machala y Ambato, consideran ventajoso el franquiciar su negocio a nivel local. Esto podría deberse a que el nivel de ingresos de la población ecuatoriana es mayor en el área urbana (Instituto Nacional de Estadística y Censos-INEC, 2016). En virtud de este crecimiento, es recomendable que los empresarios, antes de iniciar la búsqueda de interesados en obtener la licencia de su negocio, registren su marca en el organismo competente.

\subsection{Las franquicias ecuatorianas en la oferta de bienes y servicios}

La mayor preocupación tanto para los gobiernos como para la comunidad global es el lograr ampliar las oportunidades para los habitantes de los países en desarrollo; por tanto, cabe resaltar que, en Ecuador existe la tendencia de crear 
franquicias, con el fin de generar puestos de empleo, al mismo tiempo que el emprendedor obtiene independencia económica y se reduce la pobreza en el país (Diario La Hora, 2013); lo que ha permitido que las franquicias alcancen un considerable impulso en los últimos diez años (Guerrero, 2015). El Instituto Nacional de Estadística y Censos (2016) señala que durante el período comprendido entre junio 2010 a junio 2016, la tasa de desempleo pasó del $8.2 \%$ al $5.7 \%$ a nivel nacional; además, la tasa global de participación laboral se situó en un $67.8 \%$; esto significa que existe en el Ecuador una mayor oferta laboral que el número de personas que ingresó al mercado de trabajo.

Además, la tasa de subempleo ha permanecido constante $(50 \%)$ desde el año 2007 hasta el 2013, año en el que este indicador se colocó en un 52.49\%; por lo que se considera que el desempleo es un problema estructural que no se puede eliminar mientras no se otorgue impulso a la productividad de las empresas del país a través de ofrecer mayor desarrollo a la inversión en el sector privado, lo que generaría mayor producción y fuentes de empleo (Diario El Comercio, 2013). Además, se realizó un análisis de la evolución del empleo desde el año 2010 hasta el año 2016, el detalle se exhibe en la Tabla 1.

Tabla 1: Evolución del empleo en Ecuador

\begin{tabular}{|l|c|c|c|c|}
\hline PERÍODO & TEA & TSE & TOENP & TENR \\
\hline Diciembre 2010 & $44.70 \%$ & $13.80 \%$ & $27.40 \%$ & $8.20 \%$ \\
\hline Diciembre 2011 & $45.50 \%$ & $10.70 \%$ & $31.30 \%$ & $7.70 \%$ \\
\hline Diciembre 2012 & $46.50 \%$ & $\mathbf{9 . 0 0 \%}$ & $30.10 \%$ & $8.00 \%$ \\
\hline Diciembre 2013 & $47.89 \%$ & $11.60 \%$ & $29.00 \%$ & $7.10 \%$ \\
\hline Diciembre 2014 & $\mathbf{4 9 . 3 0 \%}$ & $12.90 \%$ & $26.80 \%$ & $\mathbf{7 . 1 0 \%}$ \\
\hline Diciembre 2015 & $46.50 \%$ & $14.00 \%$ & $26.40 \%$ & $7.70 \%$ \\
\hline Diciembre 2016 & $41.20 \%$ & $19.90 \%$ & $\mathbf{2 5 . 1 0 \%}$ & $8.40 \%$ \\
\hline
\end{tabular}

Nota: Tasa de Empleo Adecuado = TEA, Tasa de Subempleo = TSE, Tasa de Otro empleo no pleno $=$ TOENP, Tasa de empleo no remunerado $=$ TENR.

Fuente: Elaboración propia con base en los datos estadísticos de la Encuesta Nacional de Empleo, Desempleo y Subempleo. Indicadores Laborales. Junio 2017. Recuperado de la página web: http://www.ecuadorencifras.gob.ec/documentos/web-inec/EMPLEO/2017/Junio/062017_Presentacion_M.Laboral.pdf 
En los datos sobre la evolución del empleo en Ecuador se destaca que la tasa más alta de empleo adecuado, se presentó en el año 2014 (49.30\%), mientras que la tasa más baja de subempleo $(9.0 \%)$ se presentó en el año 2012 , la tasa más baja de otro empleo no pleno (25.10\%) se exhibe en el año 2016 y la tasa más baja de empleo no remunerado (7.10\%) se presentó en los años 2013 y 2014. En la misma línea, Guerrero (2015) y la Asociación Ecuatoriana de Franquicias-AEFRAN (2018), señalan que cada franquicia nacional generó en promedio alrededor de 702 empleos directos, 244 fuentes de empleo indirecto y 25 personas subempleadas por cada franquicia ecuatoriana; por lo que, de acuerdo con la legislación ecuatoriana, para legalizar el trabajo del personal se debe generar un contrato de trabajo.

En Ecuador, con base en el Código del Trabajo (Ecuador Legal, 2017) todo trabajo será remunerado y los derechos de los trabajadores son irrenunciables, lo que se debe reflejar en un contrato individual ${ }^{4}$ de trabajo; estos contratos se basan en el artículo 79 del Código de Trabajo, el cual señala que el contratante tiene la facultad de estipular libremente los sueldos, pero en ningún caso este podrá ser menor al salario mínimo vital.

El Código del Trabajo señala que los contratos pueden ser, por su forma de elaboración: expreso o tácito; por la forma de remuneración: a sueldo $0^{5}$ a jornal, en participación y mixto; por el tiempo de suscripción: por tiempo indefinido, de temporada, eventual y ocasional; por el tipo de trabajo: por obra cierta, por obra o servicio determinado dentro del giro del negocio, por tarea y a destajo; por el número de contratados: individual, de grupo o por equipo (Ecuador Legal, 2017).

En este orden de ideas, la Cámara de Comercio Ecuatoriano-Americana; Prom-Perú (2011) señala que la empresa consultora Deloitte realizó un estudio en el que ha identificado que existen áreas en las que las franquicias demandan más personal, tales como: operaciones, mercadeo y ventas, finanzas y talento humano.

4 El contrato individual de trabajo es un convenio mediante el cual un individuo se compromete con otro $u$ otros a ofrecer sus servicios de una manera lícita, bajo relación de dependencia a cambio de una remuneración fijada en dicho convenio (Ecuador Legal, 2017).

5 El contrato a sueldo es un contrato en el que se define la remuneración con base en un día de trabajo o de estar a disposición del jefe; no se considera la cantidad de trabajo realizado para estipular el pago (Ecuador Legal, 2017). 
El Gerente en Ecuador de la Asociación Ecuatoriana de Franquicias-AEFRÁN (2018), señala que el modelo de las franquicias es una manera segura de invertir, tanto para el emprendedor que desea montar un negocio, como para el dueño de un negocio de éxito que desea crecer; de manera que muchos inversionistas han ingresado a nuevos conceptos de negocio bajo el formato de las franquicias; sin embargo, los emprendedores ecuatorianos muestran mayor interés por las franquicias cuyas licencias oscilen entre $\$ 10000$ y $\$ 25000$ USD; esta situación ha generado el incremento en la oferta de empleo, lo que ha permitido la dinamización de la economía.

\section{Materiales y Métodos}

El presente estudio se llevó a cabo con el objetivo de caracterizar las franquicias ecuatorianas e identificar su aporte en la generación de fuentes de empleo; para ello se realizó un estudio no experimental, de corte transversal, de tipo descriptivo. El enfoque utilizado en la investigación fue mixto, el cual se realizó en dos fases, la fase cualitativa se realizó mediante la aplicación de una entrevista semi estructurada, a los directores generales de dos de las asociaciones de franquicias más representativas del país, la cual constó de 7 preguntas enfocadas en conocer desde la perspectiva de los entrevistados, el ecosistema de franquicias y su evolución en el Ecuador. Las preguntas se direccionaron hacia solicitar la opinión de los entrevistados respecto a los factores de éxito y las dificultades que podrían enfrentar las franquicias nacionales en el mercado; además, se les consultó sobre el aporte de las franquicias ecuatorianas al dinamismo de la economía y en la generación de fuentes de empleo, finalizando con el pedido de que realicen recomendaciones generales para mejorar el sistema de franquicias en el país.

Para la fase cuantitativa se realizó un censo a todas las franquicias nacionales existentes al momento de realizar la presente investigación (45 elementos), debido a que se buscó analizar la población total de las empresas cuya idea de negocio tuviese origen ecuatoriano y que se encontraban trabajando bajo el modelo de franquicias al momento de realizar el presente estudio. El instrumento utilizado fue un cuestionario estructurado, conformado por 31 preguntas direc- 
cionadas a describir la situación actual de este modelo de negocios; el cuestionario contó con varias dimensiones, tales como: información sociodemográfica, información general, información interna, características ambiente laboral y características financieras; se examinaron tanto la fiabilidad como la validez de las escalas mediante un análisis factorial exploratorio, el cual facilitó identificar que los enunciados utilizados en el cuestionario estructurado pertenecían al mismo constructo (Bagozzi \& Yi, 2012).

Tanto la fase cualitativa como la cuantitativa, se las realizó en el período abrilagosto de 2016, para luego dar paso a la fase de interpretación de los datos obtenidos de cada variable utilizada en los instrumentos de medición, para ello se utilizó la estadística descriptiva y un análisis de correlación, con el fin de caracterizar a las franquicias de origen ecuatoriano y su contribución en la generación de fuentes de empleo.

\section{Resultados y Discusión}

Una vez realizadas las entrevistas a los representantes de las franquicias, se obtuvieron los resultados cualitativos, los cuales reflejan que en Ecuador los empresarios ven muy fortalecido al modelo de negocios de las franquicias; por otro lado, luego de haber aplicado la encuesta al total de las franquicias creadas con capital ecuatoriano, se obtuvieron los resultados de la fase cuantitativa, los mismos que se detallan en el siguiente apartado.

\subsection{Resultados}

De acuerdo con el análisis de las entrevistas realizadas, se identificó que en Ecuador no hay una ley enfocada en las franquicias, pero se cuenta con el apoyo del Instituto Ecuatoriano de Propiedad Intelectual (IEPI), institución en la que se realiza la inscripción de una marca; además, las franquicias se apoyan en el Código Civil, lo que admite una adecuada relación entre las partes. Así mismo, los entrevistados señalan que no existe ningún factor que garantice el éxito en una franquicia, sin embargo, estas minimizan el 
riesgo en la inversión, gracias a que permiten acceder de manera directa al uso de una marca exitosa, manuales de operación, procesos definidos, alternativas de capacitación y el compromiso del franquiciado. Sin embargo, los entrevistados anotan que las franquicias nacionales presentan algunas dificultades, originadas en la falta de apoyo por parte de entes gubernamentales o de organizaciones privadas, para lo que recomiendan que se genere un compromiso conjunto, entre la academia, la empresa y el estado, con el fin de difundir este modelo de expansión empresarial que aportan al dinamismo económico del país, ya que a través de la apertura de una franquicia se generan fuentes de empleo.

De manera complementaria, los resultados obtenidos a través de las encuestas reflejan que existen 45 franquicias creadas con capital ecuatoriano, las cuales han aperturado 2355 locales, los cuales facturan un promedio de $\$ 1.203$ millones de dólares americanos al año y generan 12114 empleos, dichas franquicias tienen mayor presencia en la ciudad de Quito (516 locales), en segundo lugar, se encuentran en la ciudad de Guayaquil (371 locales) y en tercer lugar en la ciudad de Cuenca (II4 locales). Las franquicias bajo estudio, se clasifican según el sector económico en el que se desenvuelven, en: empresas enfocadas al sector de servicios (34), las cuales poseen alrededor de 599 establecimientos; empresas dedicadas al comercio (7), con 1491 establecimientos y las de manufactura (7), con 265 establecimientos.

En la Tabla 2 se detalla la distribución de las franquicias según el tipo de industria en la que estas desarrollan sus actividades, tales como: alimenticia, retail o servicios; además se revela el número de establecimientos que poseen y su respectivo porcentaje de participación de mercado; se destaca la industria de alimentos puesto que exhibe el mayor porcentaje (62\%) de franquicias, seguidas por las franquicias de la industria de retail y, por último, las de servicios. 
Tabla 2: Distribución de las franquicias según el tipo de industria

\begin{tabular}{|l|c|c|l|}
\hline Industria & NF & $\%$ & \multicolumn{1}{c|}{ Nombre de la franquicia } \\
\hline Alimentos & 30 & $\mathbf{6 2 \%}$ & $\begin{array}{l}\text { Akai Sushi Express, Bopan Centro, Cassave, } \\
\text { Chicken \& Chicken, Churrin Churrón, Escoffee, } \\
\text { Frozyu Frozen Yogurt, GreenFrost, Heladerías } \\
\text { Tutto Freddo, Jimmy Huber, Koktlitos, La Parrilla } \\
\text { de Homero, La Tablita del Tártaro, Los Ceviches } \\
\text { de la Rumiñahui Los Hot Dogs de la González } \\
\text { Suárez, Movie House Pizza, Nice Cream } \\
\text { Heladería, Panadería Arenas , Panificadora } \\
\text { Ambato, Papitas Fritas a lo Bestia, Pim's, Pizza } \\
\text { Planet, Rikoko, Sake Restaurantes, Sport Planet, } \\
\text { Sweet \& Coffee, Wings Xpress, Yoguberry, } \\
\text { Yogurt de la Amazonas, Yogurt Persa. }\end{array}$ \\
\hline Retail & 12 & $25 \%$ & $\begin{array}{l}\text { Disensa, Comisariato de Mascotas, Cruz } \\
\text { Azul, Dolce, Edimca, Expocolor, Farmacias } \\
\text { Comunitarias, Farmacias Económicas, Medicity, } \\
\text { Pañaleras Pototín, Pinto, Teleshop. }\end{array}$ \\
\hline Servicios & 6 & $13 \%$ & $\begin{array}{l}\text { Bit Company, Cellshop, Dinadec, Diafoot, } \\
\text { Docucentro Xerox, Healthy feet }\end{array}$ \\
\hline
\end{tabular}

Nota. Número de franquicias $=$ NF, Porcentaje $=\%$.

Fuente: Elaboración propia con base en Aigaje-Sierra (2017). El aporte de las franquicias ecuatorianas como modelo de crecimiento empresarial en el ámbito económico y social. Universidad de las Fuerzas Armadas ESPE. Tesis de Pregrado. Carrera de Ingeniería Comercial. Recuperado de: http://repositorio.espe.edu.ec/handle/21000/12189

De los resultados obtenidos en la encuesta aplicada a los dueños de las franquicias, se identificó que el costo promedio para invertir en una franquicia ecuatoriana varía desde los $\$ 10.000$ USD por adquirir una franquicia pequeña, pasando por los $\$ 40.000$ de inversión para adquirir una franquicia mediana, hasta un tope de $\$ 80.000$ dólares por obtener una franquicia de origen nacional considerada grande; el costo depende tanto de la marca como de las características del local: tamaño, localización, adecuaciones, entre otros aspecto. En el caso de algunas franquicias se debe incurrir en costos adicionales para adquirir el inventario inicial y mobiliario extra; es decir la inversión total, para adquirir una franquicia 
ecuatoriana, varía dependiendo de las características de la misma, pero sus costos son menores en comparación a los de adquisición de las franquicias internacionales ofertadas en el mercado ecuatoriano.

La cobertura de las franquicias ecuatorianas se encuentra distribuida en 23 provincias del Ecuador, siendo la provincia de Pichincha la que exhibe la mayor concentración de establecimientos (762), seguida de Guayas y Azuay (598 y 118, respectivamente); la provincia con la menor cobertura es Galápagos (10 establecimientos); empresas como Pañaleras Pototín, Akai Sushi Express, Pinto, Los Ceviches de la Rumiñahui y Sake Restaurantes, cuentan con cobertura internacional, con establecimientos (19) en países como: Colombia, Estados Unidos, Perú, Venezuela, Bolivia, Panamá, Costa Rica, Puerto Rico y República Dominicana.

La franquicia nacional más representativa es la de los Cebiches de la Rumiñahui, la cual inició sus actividades en el año de 1985 y que a la fecha del estudio contaba con 44 establecimientos en todo el país y dos en el exterior (uno en Estados Unidos y otro en Colombia. Se observa que las franquicias que pertenecen a la industria de alimentos son las que poseen un mayor porcentaje de empleados por franquicia de origen nacional; cuya proporción varía en función de la ciudad en la que estas están localizadas, los detalles se exhiben en la Tabla 3.

Tabla 3: Porcentajes del número de empleados por tipo de franquicia y por ciudad

\begin{tabular}{|c|c|c|c|c|c|c|c|c|c|c|c|}
\hline \multirow{2}{*}{$\begin{array}{l}\text { Promedio de } \\
\text { empleados } \\
\text { por franquicia }\end{array}$} & \multirow{2}{*}{$\begin{array}{c}\text { Industria a la } \\
\text { que pertenece } \\
\text { la franquicia }\end{array}$} & \multicolumn{2}{|c|}{ Quito } & \multicolumn{2}{|c|}{ Guayaquil } & \multicolumn{2}{|c|}{ Cuenca } & \multicolumn{2}{|c|}{$\begin{array}{c}\text { Otras } \\
\text { ciudades }\end{array}$} & \multicolumn{2}{|c|}{ Internaciona } \\
\hline & & $f$ & $\%$ & $f$ & $\%$ & $f$ & $\%$ & $f$ & $\%$ & $f$ & $\%$ \\
\hline \multirow[t]{4}{*}{1 a 3} & Retail & 2 & $5 \%$ & 1 & $4 \%$ & 1 & $8 \%$ & 1 & $5 \%$ & 1 & $14 \%$ \\
\hline & Alimentación & 8 & $22 \%$ & 5 & $19 \%$ & 1 & $8 \%$ & 5 & $26 \%$ & 2 & $29 \%$ \\
\hline & \begin{tabular}{|l|} 
Servicios \\
\end{tabular} & 2 & $5 \%$ & 0 & $0 \%$ & 0 & $0 \%$ & 0 & $0 \%$ & 0 & $0 \%$ \\
\hline & Total & 12 & $32 \%$ & 6 & $23 \%$ & 2 & $15 \%$ & 6 & $32 \%$ & 3 & $43 \%$ \\
\hline \multirow[t]{4}{*}{4 a 6} & Retail & 4 & $11 \%$ & 4 & $15 \%$ & 4 & $31 \%$ & 2 & $11 \%$ & 1 & $14 \%$ \\
\hline & Alimentación & 8 & $22 \%$ & 8 & $31 \%$ & 3 & $23 \%$ & 6 & $32 \%$ & 1 & $14 \%$ \\
\hline & Servicios & 3 & $8 \%$ & 2 & $8 \%$ & 1 & $8 \%$ & 1 & $5 \%$ & 0 & $0 \%$ \\
\hline & Total & 15 & $41 \%$ & 14 & $54 \%$ & 8 & $62 \%$ & 9 & $47 \%$ & 2 & $29 \%$ \\
\hline
\end{tabular}




\begin{tabular}{|c|c|c|c|c|c|c|c|c|c|c|c|}
\hline \multirow[t]{4}{*}{1 a 9} & Retail & 1 & $3 \%$ & 1 & $4 \%$ & 0 & $0 \%$ & 1 & $5 \%$ & 0 & $0 \%$ \\
\hline & Alimentación & 6 & $16 \%$ & 3 & $12 \%$ & 1 & $8 \%$ & 2 & $11 \%$ & 1 & $14 \%$ \\
\hline & Servicios & 0 & $0 \%$ & 0 & $0 \%$ & 0 & $0 \%$ & 0 & $0 \%$ & 0 & $0 \%$ \\
\hline & Total & 7 & $19 \%$ & 4 & $15 \%$ & 1 & $8 \%$ & 3 & $16 \%$ & 1 & $14 \%$ \\
\hline \multirow[t]{4}{*}{10 a 12} & Retail & 0 & $0 \%$ & 0 & $0 \%$ & 0 & $0 \%$ & 0 & $0 \%$ & 0 & $0 \%$ \\
\hline & Alimentación & 2 & $5 \%$ & 1 & $4 \%$ & 1 & $8 \%$ & 1 & $5 \%$ & 1 & $14 \%$ \\
\hline & Servicios & 0 & $0 \%$ & 0 & $0 \%$ & 0 & $0 \%$ & 0 & $0 \%$ & 0 & $0 \%$ \\
\hline & Total & 2 & $5 \%$ & 1 & $4 \%$ & 1 & $8 \%$ & 1 & $5 \%$ & 1 & $14 \%$ \\
\hline \multirow[t]{4}{*}{ más de 13} & Retail & 0 & $0 \%$ & 0 & $0 \%$ & 0 & $0 \%$ & 0 & $0 \%$ & 0 & $0 \%$ \\
\hline & Alimentación & 1 & $3 \%$ & 1 & $4 \%$ & 1 & $8 \%$ & 0 & $0 \%$ & 0 & $0 \%$ \\
\hline & Servicios & 0 & $0 \%$ & 0 & $0 \%$ & 0 & $0 \%$ & 0 & $0 \%$ & 0 & $0 \%$ \\
\hline & Total & 1 & $3 \%$ & 1 & $4 \%$ & 1 & $8 \%$ & 0 & $0 \%$ & 0 & $0 \%$ \\
\hline \multirow[t]{4}{*}{ Total } & Retail & 7 & $19 \%$ & 6 & $23 \%$ & 5 & $38 \%$ & 4 & $21 \%$ & 2 & $29 \%$ \\
\hline & Alimentación & 25 & $68 \%$ & 2 & $8 \%$ & 7 & $54 \%$ & 14 & $74 \%$ & 5 & $71 \%$ \\
\hline & \begin{tabular}{|l|} 
Servicios \\
\end{tabular} & 5 & $14 \%$ & 18 & $69 \%$ & 1 & $8 \%$ & 1 & $5 \%$ & 0 & $0 \%$ \\
\hline & \begin{tabular}{|l|} 
Total \\
\end{tabular} & 37 & $100 \%$ & 26 & $100 \%$ & 13 & $100 \%$ & 19 & $100 \%$ & 7 & $100 \%$ \\
\hline
\end{tabular}

Nota. Frecuencia = f, Porcentaje $=\%$.

Fuente: Elaboración propia con base en resultados de la encuesta aplicada a los dueños de franquicias de capital nacional.

En la Tabla 3 se refleja que, en la ciudad de Quito, el mayor porcentaje global en el número de empleados (68\%), corresponde al sector de alimentos, cabe destacar que se identifica que, para esa ciudad, el mayor porcentaje (22\%) de empleados del sector de alimentos, se encuentra dentro del rango de 1 a 3 empleados, así como en el rango de 4 a 6 empleados. Así mismo, en la ciudad de Cuenca el mayor porcentaje global (54\%) de empleados, también corresponde al sector de alimentos y se observa que el mayor porcentaje (23\%) de trabajadores se encuentra en el de las franquicias que tienen contratados de 4 a 6 empleados. En otras ciudades el mayor porcentaje global $(74 \%)$ de personas contratadas, también corresponde al sector de alimentos, donde el mayor promedio por rangos (32\%) corresponde al de 4 a 6 empleados.

Lo mismo ocurre a nivel internacional, donde el porcentaje global más alto $(71 \%)$, también corresponde a la industria de alimentos, sin embargo, la mayor parte de estas franquicias tiene contratado de 1 a 3 empleados en mayor porcentaje 
(29\%). En cambio, en la ciudad de Guayaquil, el mayor porcentaje global de empleados (69\%), corresponde a las franquicias del sector de servicios, donde el mayor porcentaje de trabajadores (31\%) se encuentra en las franquicias que poseen de 4 a 6 empleados. Una vez revisados los datos relevantes, se denota que en la industria de alimentos es donde se contrata más personal.

Para los encuestados, es importante que se cumpla con las condiciones de trabajo adecuadas, destacando que el ambiente físico debe ser óptimo, además, se debe contar con los recursos suficientes para que los empleados realicen sus labores; en relación al contrato laboral que manejan las franquicias, en relación al tipo de contrato utilizado para contratar al personal, la mayoría (92\%) de los encuestados indica que utilizan el contrato a sueldo, ya que este tipo de contrato cumple con todas las reglamentaciones del Código del Trabajo.

Además, los resultados de la encuesta reflejan que las franquicias de origen nacional, en la actualidad, han incrementado el número de franquicias otorgadas, las mismas que tienen presencia tanto a nivel nacional como internacional, las cuales generan de manera global 12114 plazas de trabajo, lo que permite afirmar que el modelo de negocio de las franquicias, permite incrementar el volúmen de personas contratadas para brindar sus servicios en los establecimientos creados bajo la figura de las franquicias, las mismas que bajo este mecanismo, encuentran un camino para fortalecer su marca; el detalle de las franquicias en orden descendente, considerando el número de franquicias que posee cada negocio, se presenta en la Tabla 4.

Tabla 4: Detalle del número de franquicias y de empleos generados

\begin{tabular}{|l|c|c|c|}
\hline \multicolumn{1}{|c|}{ Nombre de la franquicia } & NF & PE & NTE \\
\hline Disensa & 538 & 5 & 2.690 \\
\hline Cruz Azul & 390 & 5 & 1.950 \\
\hline Farmacias Económicas & 350 & 5 & 1.750 \\
\hline Pañaleras Pototín & 149 & 4 & 596 \\
\hline Farmacias Comunitarias & 90 & 5 & 450 \\
\hline Medicity & 85 & 5 & 425 \\
\hline
\end{tabular}




\begin{tabular}{|c|c|c|c|}
\hline Nombre de la franquicia & NF & PE & NTE \\
\hline Sweet \& Coffee & 67 & 7 & 469 \\
\hline Papitas Fritas a lo Bestia & 54 & 4 & 216 \\
\hline Los Ceviches de la Rumiñahui & 44 & 11 & 484 \\
\hline Pinto & 43 & 5 & 215 \\
\hline GreenFrost & 40 & 4 & 160 \\
\hline Panificadora Ambato & 39 & 5 & 195 \\
\hline La Tablita del Tártaro & 38 & 7 & 266 \\
\hline Panadería Arenas & 36 & 6 & 216 \\
\hline Teleshop & 35 & 4 & 140 \\
\hline Yogurt Persa & 35 & 6 & 210 \\
\hline Heladerías Tutto Freddo & 34 & 5 & 170 \\
\hline Dinadec & 27 & 5 & 135 \\
\hline Koktelitos & 25 & 3 & 75 \\
\hline Expocolor & 21 & 6 & 126 \\
\hline Cellshop & 19 & 5 & 95 \\
\hline Los Hot Dog's de la González Suárez & 19 & 10 & 190 \\
\hline Nice Cream Heladería & 17 & 4 & 68 \\
\hline Akai Sushi Express & 12 & 6 & 72 \\
\hline Jimmy Huber & 12 & 5 & 60 \\
\hline Yogurt de la Amazonas & 12 & 4 & 48 \\
\hline Comisariato de Mascotas & 11 & 6 & 66 \\
\hline Chicken \& Chicken & 10 & 5 & 50 \\
\hline Cassave & 9 & 4 & 36 \\
\hline Sport Planet & 9 & 11 & 99 \\
\hline Docucentro Xerox & 8 & 5 & 40 \\
\hline Rikoko & 8 & 3 & 24 \\
\hline Wings Xpress & 8 & 5 & 40 \\
\hline Yoguberry & 6 & 3 & 18 \\
\hline Churrín Churrón & 6 & 5 & 30 \\
\hline Pim's & 6 & 8 & 48 \\
\hline
\end{tabular}




\begin{tabular}{|l|c|c|c|}
\hline \multicolumn{1}{|c|}{ Nombre de la franquicia } & NF & PE & NTE \\
\hline Diafoot & 6 & 3 & 18 \\
\hline Edimca & 5 & 6 & 30 \\
\hline Frozyu Frozen Yogurt & 5 & 5 & 25 \\
\hline Sake Restaurantes & 5 & 5 & 25 \\
\hline Pizza Planet & 4 & 5 & 20 \\
\hline Bopan Centro & 3 & 4 & 12 \\
\hline Dolce & 3 & 2 & 6 \\
\hline Escoffee & 3 & 5 & 15 \\
\hline Movie House Pizza & 3 & 5 & 15 \\
\hline Bit Company & 2 & 4 & 8 \\
\hline Healthy Feet & 2 & 2 & 4 \\
\hline La Parrilla de Homero & 2 & 7 & 14 \\
\hline
\end{tabular}

Nota: Número de franquicias $=$ NF, promedio de empleados $=P E$, número total de empleados $=$ NTE.

Fuente: Elaboración propia con base en resultados de la encuesta aplicada a los dueños de franquicias de capital nacional.

De lo arriba señalado, se denota que el sistema de franquicias contribuye con el crecimiento del negocio de cada una de los franquiciados, a su vez, dicho desarrollo está estrechamente relacionado con la generación de empleos, por lo que se determina que las franquicias nacionales analizadas al momento del estudio, poseían alrededor de 2355 establecimientos y que cada uno de estos ha creado en promedio, entre cuatro y seis fuentes de empleo, lo que a su vez generó un total de 12114 empleos a nivel nacional.

\subsection{Discusión}

Palomeque y Ramírez (2012), destacan que las franquicias en el sector de alimentación son las más desarrolladas, situando al Ecuador como el país en el que los negocios dedicados a la gastronomía y a las comidas rápidas, son los que han crecido con mayor rapidez, afirmación que coincide con los hallazgos del presente estudio. Se destaca el caso de los Cebiches de la Rumiñahui, franquicia que comenzó a operar hace aproximadamente 33 años y ha presentado 
crecimiento sostenido tanto a nivel nacional como internacional, de acuerdo con Meléndez (2013) que los factores del éxito de esta franquicia, son: ofrecer productos de calidad, respetar los procesos, la estandarización, capacitar continuamente a su personal y tener factores diferenciadores.

Así mismo, los resultados de la presente investigación coinciden con el estudio realizado por Palomeque y Ramírez (2012), que trata del perfil del mercado de las franquicias en el Ecuador, donde se evidencia que las franquicas que operan en el país generan empleos directos; de igual manera, los estudios realizados por Guerrero (2015) y la Asociación Ecuatoriana de Franquicias-AEFRAN (2018), coinciden al indicar que cada franquicia nacional generó empleos directos e indirectos.

Estos datos obtenidos confirman que las franquicias ecuatorianas brindan un gran dinamismo a la economía, ya que, al crear nuevas empresas, estas necesitan de mayor cantidad de insumos y servicios para funcionar, además de personal para brindar sus servicios, por ende, este conjunto de elementos fomenta la generación de empleos para en el Ecuador.

\section{Conclusiones}

- La evolución del sistema de franquicias en el Ecuador ha sido lenta en relación a la rapidez con que este modelo ha crecido en los vecinos países latinoamericanos de Brasil y México, donde el sistema de franquicias cuenta con un ecosistema totalmente avanzado.

- El progreso de las franquicias ecuatorianas ha sido notorio en los últimos años, especialmente las franquicias dedicadas a la industria de alimentos, las cuales comprenden más de la mitad de las franquicias nacionales que están en el mercado.

- La franquicia como modelo de negocio aumenta la oferta de empleo y al mismo tiempo fomenta la creación de nuevas micro empresas que gracias a este sistema pueden fortalecer su marca y darla a conocer a nivel nacional e inclusive en mercados fuera del país.

- Convertir una empresa al modelo de franquicias para su crecimiento, o invertir en una franquicia nacional, es una opción muy favorable, debido a que de esta manera se minimiza el riesgo en la inversión. 


\section{Referencias bibliográficas}

- Aigaje-Sierra, W. M. (2017). El aporte de las franquicias ecuatorianas como modelo de crecimiento empresarial en el ámbito económico y social. Sangolquí, Ecuador: Universidad de las Fuerzas Armadas ESPE. Tesis de Pregrado. Carrera de Ingeniería Comercial.

- Asociación Ecuatoriana de Franquicias - AEFRAN. (2018). Creación de Franquicias en Ecuador . Obtenido de Guido Santillán Mancero : https:// aefran.org/franquicie-su-negocio/

- Asociación Mexicana de Franquicias, A. (2017). Asociación Mexicana de Franquicias. Obtenido de Preguntas frecuentes: http://franquiciasdemexico.org.mx/conoce-a-la-asociacion-mexicana-de-franquicias/preguntas-frecuentes/

- Bagozzi, R. P., \& Yi, Y. (2012). Specification, Evaluation, and Interpretation of Structural Equation Models. Journal of the Academy of Marketing Science, 40(1), 8-34.

- Cajamarca, M., \& Granda, P. (2012). Análisis de las franquicias en el Ecuador. Cuenca: Trabajo previo a la obtención del grado de Ingeniera Comercial Universidad de Cuenca. Facultad de Ciencias Económicas y Administrativas. Obtenido de http://dspace.ucuenca.edu.ec/handle/123456789/1077

- Cámara de Comercio Ecuatoriano-Americana; Prom-Perú. (2011). Perfil de mercado de franquicias en Ecuador. Obtenido de Servicios al exportador. Informes especializados: http://www.siicex.gob.pe/siicex/documentosportal/alertas/documento/doc/1025350155rad0586F

- Definición, a. (14 de agosto de 2016). Definición y etimología de franquicia. Obtenido de Bogotá: E-Cultura Group: https://definiciona.com/franquicia/

- Diario El Comercio. (2013). El subempleo no bajó del 50\% en siete años. Obtenido de http://www.elcomercio.com/actualidad/negocios/subempleono-del-50-siete.html

- Diario La Hora. (31 de octubre de 2013). Un negocio donde todos ganan. La micro franquicia social 'Al pasito sabrosito' deja buenos resultados en sus primeros cinco meses. Obtenido de https://lahora.com.ec/noticia/1101585121/noticia 
- Ecuador Legal. (2017). Ecuador Legal on line. Código del Trabajo. Obtenido de http://www.ecuadorlegalonline.com/laboral/codigo-de-trabajo/

- Fernández, Luis. (04 de enero de 2017). Definanzas.com . Obtenido de Empresas, Negocios y Pymes: https://definanzas.com/integracion-vertical/

- Guerrero, M. (2015). El empleo directo e indirecto que generan las franquicias nacionales en la ciudad de Quito. Tesis previa a la obtención del Grado de Master en Gerencia de la Calidad y Productividad con normas ISO . Quito, Pichincha, Ecuador: Pontificia Universidad Católica del Ecuador.

- Guerrero-Calderón, M. (2015). El empleo directo e indirecto que generan las franquicias nacionales en la ciudad de Quito. (F. d. Contables, Ed.) Quito: Pontificia Universidad Católica del Ecuador.

- Instituto Nacional de Estadística y Censos (INEC). (julio de 2016). INEC publica cifras del mercado laboral de junio 2016. Obtenido de Encuesta Nacional de Empleo, Desempleo y Subempleo Resultados Junio 2016: Recuperado de http://www.ecuadorencifras.gob.ec/inec-publica-cifras-del-mercado-laboral-de-junio-2016/

- Instituto Nacional de Estadística y Censos-INEC. (julio de 2016). INEC publica cifras del mercado laboral de junio 2016. Obtenido de Encuesta $\mathrm{Na}-$ cional de Empleo, Desempleo y Subempleo Resultados Junio 2016: Recuperado de http://www.ecuadorencifras.gob.ec/inec-publica-cifras-del-mercado-laboral-de-junio-2016/

- Llain-Arenilla, S., \& Insignares-Cera, S. (2016). Efectos del Tratado de Libre Comercio entre Colombia y Estados Unidos en torno al Contrato de Franquicia Internacional. Vniversitas, 21-57.

- Medina, D. (2016). Impacto económico de la franquicia a nivel mundial y su presencia local en latinoamérica. Quito, Pichincha, Ecuador: Escuela Politécnica Nacional.

- Meléndez, Á. (2013). El fértil mercado de las franquicias de comida. Quito, Ecuador: Revista Gestión.

- Palomeque, J., \& Ramírez, F. (2012). Perfil de mercado de franquicias en Ecuador. Quito, Pichincha, Ecuador: Cámara de Comercio Ecuatoriana Americana.

- Pavón-Villegas, C., \& Vargas-Hernández, J. (2016). Consideraciones sobre el auge de las franquicias como sistema de negocios en México. Gestión y Estratégias, número 49(ISSN 1606-8459), 83-91. 
- RAE, R.-A.-E. (2014). Diccionario de la lengua española, 23. a edición. Madrid: Espasa.

- Ramos-Mallarino, J., \& Forero-Rodríguez, D. (2014). La integración vertical en la Administración Logística de la Escuela Militar de Cadetes. Revista Científica "General José María Córdova”, 12 (13), 259-274.

- Vásquez-Gómez, A. S. (6 de diciembre de 2017). Análisis de las franquicias existentes en la ciudad de Esmeraldas. Tesis previa obtención del título de Ingeniero/a en Comercio Exterior . (E. d. Exterior, Ed.) Ecuador : PUCESE . 